\title{
Discussões em torno do processo de judicialização dos direitos fundamentais previdenciários*
}

\section{Discussions around the process of judicialization of fundamental social security rights}

\author{
Julia Lenzi Silva* \\ Juliana Presotto Pereira Netto**
}

\section{Resumo}

O presente artigo intenta problematizar o crescente processo de judicialização das políticas públicas relativas à previdência social, ressaltando as especificidades desse fenômeno e buscando passar ao largo dos argumentos retórico-simplificados, uma vez que impossibilitam o alcance de uma compreensão mais aprofundada do complexo contexto em que se insere essa dinâmica social. A partir da categoria de políticas públicas constitucionais vinculadas, discute-se o paradoxo existente entre a constitucionalização dos direitos sociais (essencialmente prestacionais) na Constituição de 1988 e a adoção do neoliberalismo como política de Estado, cujas diretrizes centrais propugnam pela diminuição do aparelho estatal e redução dos gastos sociais. Contextualizado o grave descompasso entre o ser e dever-ser da legislação social no âmbito da lógica de mercado, passa-se à caracterização do processo previdenciário, salientando suas especificidades e denunciando que elas não vêm sendo consideradas pela lógica estritamente econômica

Este trabalho foi apresentado originalmente no II Encontro Procad (UFAL, UFPE, UFPB) - "O Judiciário e o discurso dos Direitos Humanos" -, realizado na Faculdade de Direito de Recife, entre os dias 23 a 25 de novembro de 2011. Somos gratas ao Prof. George Sarmento e aos demais participantes do grupo de trabalho "o discurso da efetividade dos direitos sociais no judiciário" pelos comentários valiosos a uma versão inicial deste artigo. Cabem aqui as ressalvas habituais.

* Bacharela e mestranda em Direito pela Universidade Estadual Paulista Julio de Mesquita Filho - UNESP, campus de Franca-SP, sob a orientação da Profa. Dra. Juliana Presotto Pereira Netto. Bolsista FAPESP. Membro do Núcleo de Estudos de Direito Alternativo (NEDA). Franca - SP Brasil. E-mail: julia_lenzi@yahoo.com.br.

*** Professora do Curso de Direito da Universidade Estadual Paulista Julio de Mesquita Filho UNESP. Franca - SP - Brasil. E-mail: jprepen@gmail.com. 
que orienta a atuação do Instituto Nacional do Seguro Social. Nesse sentido, destaca-se a prevalência do princípio da preservação do equilíbrio financeiro e atuarial, fundamento da maioria das decisões denegativas de benefícios na esfera administrativa, em contraposição aos demais princípios que conformam a sistemática da seguridade social brasileira (art. 194, CF). Postas as premissas teóricas necessárias, foca-se a análise na atuação do Poder Judiciário enquanto ultima ratio dos vulneráveis, destacando-se sua função realizadora, cuja concreção se dá por meio de uma hermenêutica constitucional verdadeiramente comprometida com a efetivação dos comandos normativos na realidade cotidiana daqueles e daquelas que ainda permanecem estrangeiros à proteção social.

Palavras-chave: Poder Judiciário. Políticas públicas. Direitos sociais prestacionais. Processo judicial previdenciário.

\section{Abstract}

This article attempts to confront the growing process of judicialization of public policy relating to Social Security, highlighting the specificity of this phenomenon and trying to pass off the rhetorical-simplified arguments, since they make it impossible to reach a deeper understanding of the complex context in which it appears that social dynamics. From the category of public policies related constitutional, discusses the paradox between the constitutionalisation of social rights (essentially payments) in the 1988 Constitution, and the adoption of neo-liberalism as state policy, whose guidelines advocate the reduction of the central state apparatus and reduction in social spending. Contextualized the serious gap between being and should be 'social legislation within the logic of the market, is the characterization of the pension process, highlighting their specialties and complaining that they do not see it being considered by the strictly economic logic that drives the performance the National Institute of Social Security. Notably, the prevalence of the principle of preserving the financial and actuarial balance, the foundation of most decisions denied benefits at the administrative level, in contrast to other principles that make up the systematic Brazilian Social Security (Article 194, Federal Constitution). Put the necessary theoretical assumptions, the analysis focuses on the role of the judiciary as ultima ratio of the vulnerable, especially fulfilling its function, which sintering takes place by means of a constitutional hermeneutics truly committed to the enforcement of legal standards in the concrete reality and daily, of those who remain strangers in the face of social protection.

Keywords: Judiciary. Public policy. Social payments rights. Social security lawsuit. 


\title{
Introdução
}

\author{
"Não seremos uma nação enquanto um só de nós \\ permanecer estrangeiro face à proteção social, \\ despossuído, despojado de direitos e de liberdade, porque \\ luta, as 24 horas do dia, apenas para sobreviver por um \\ triz." (ABRANCHES, 1992, p. 79)
}

Com o advento da Constituição de 1988, o Estado brasileiro restou caracterizado como sendo Democrático de Direito. Tal opção política conceitual pressupõe o respeito, a validade e a concretude de dois signos essenciais a essa forma de organização estatal: a democracia e os direitos fundamentais, que devem ser compreendidos como elementos operativos-constitutivos do Estado Democrático de Direito no Brasil. Todavia, conforme destaca Leal (2006, p. 176):

[...] há um profundo esvaziamento do Estado e da Sociedade Democráticos de Direito na terra brasilis na medida em que, mesmo havendo já um significativo esclarecimento sobre os objetivos, finalidades e princípios a serem perseguidos e que informam a República Federativa, em termos de direitos, deveres e garantias, paradoxalmente, inexistem ações públicas e privadas suficientemente capazes de concretizá-los haja vista que o plano desafiante destes compromissos não reside tão somente na dimensão sintática ou semântica de suas possibilidades, mas também na pragmática, profundamente exposta às manipulações de atores sociais (fundamentalmente de mercado) que não partilham do mesmo projeto constitucional de civilidade formalmente instaurado.

Há, portanto, um profundo descompasso entre "uma constituição que reconhece e assegura direitos e uma Sociedade na qual se reconhecem violações constantes e gravíssimas dos Direitos Humanos" (LEAL, 2000, p. 165). O respectivo cenário agrava-se quando analisado da perspectiva dos direitos sociais, cujos dispositivos aparecem previstos 
em normas com propósitos compensatórios, redistributivos e protetores, que intentam romper com o primado liberal da igualdade formal ${ }^{1}$.

Especificamente no que toca ao nosso objeto de estudo, a previdência social, é de relevo destacar que, embora não haja obstáculo ao reconhecimento formal da proteção previdenciária como direito humano e fundamental - o que, inclusive, já se deu tanto no âmbito internacional (Declaração Americana de Direitos e Deveres do Homem, 1948, artigo 16; Pacto Internacional dos Direitos Econômicos, Sociais e Culturais, 1966, artigo 9; Protocolo Adicional à Convenção Americana sobre Direitos Humanos em Matéria de Direitos Econômicos, Sociais e Culturais, mais conhecido como "Protocolo de San Salvador", 1988, artigo $9^{\circ}$ ) quanto no interno (Constituição Federal, art. $6^{\circ}$ c/c art. 201) -, ainda persistem os obstáculos à realização concreta dos dispositivos normativos, notadamente em sociedades como a nossa, que vem adotando a preponderância hierárquica dos critérios de crescimento e eficiência econômica como parâmetros da atuação estatal.

Vislumbra-se que o crescente aumento do ajuizamento de demandas judiciais referentes à previdência social constitui parte do fenômeno complexo de crise de identidade epistemológica do Direito $^{2}$ e de realocação das funções dos poderes do Estado. O Poder Judiciário, sensível à pressão dos movimentos sociais, dos advogados populares e de sujeitos cada vez mais conscientes de seus direitos,

"Los derechos sociales seguirán de un "descubrimiento" elemental: la libertad está amenazada por el despotismo, pero también por el hambre y la miseria, la ignorancia y la dependencia." (PELÁEZ, 1994, p. 16)

2 "A concepção tradicional do direito como simples técnica de controle e organização social (o que implica um conhecimento jurídico meramente informativo e despolitizado a partir do sistema legal tido como completo, lógico e formalmente coerente) vem sendo contestada a partir da concepção do direito como instrumento de direção e promoção social. Essa nova percepção encara o fenômeno jurídico numa perspectiva histórica, valorizando-o antes como um método para a correção das desigualdades e consecução de padrões mínimos de equilíbrio sócio-econômico do que como uma técnica para a produção de certeza e segurança. Nesse diapasão, valoriza-se o conhecimento jurídico multidisciplinar, que parte das indagações acerca da dimensão política, das implicações sócio-econômicas e da natureza ideológica da ordem legal estabelecida." (FARIA, 2005a, p. 20) 
passa a ser buscado como ultima ratio para a correção das injustiças perpetradas por um Executivo amarrado aos ditames do mercado, e por um Legislativo historicamente comprometido com a representação das minorias abastadas.

Los jueces aparecen instalados en imaginario de la sociedad como ultima ratio, como garantes finales del funcionamiento del sistema democrático. Desacreditado el sistema político que no parece funcionar sin altas cotas de corrupción; ensanchada de manera cada vez más profunda la brecha entre representantes y representados; cercada la gobernabilidad por la lógica implacable del mercado y por la sobredeterminación de poderes transestatales y transnacionales, se ha depositado, se diría, más por razones sistemáticas que de otra índole, una mayor expectativa en la performance del Poder Judicial que en la de otros poderes de Estado. (CÁRCOVA apud LEAL, 2000, p. 177)

Nesse sentido, cumpre destacar que a atuação do Poder Judiciário no âmbito da previdência social ganha relevo por se tratar, na maioria dos casos, de processos que versam sobre prestações alimentares, porquanto o benefício pleiteado seja o garante da subsistência daqueles e daquelas que, atingidos por uma contingência social legalmente prevista, não mais encontram condições de continuar trabalhando. Ademais, uma vez que tutela o direito fundamental à proteção social, o processo judicial previdenciário caracteriza-se por múltiplas especificidades, as quais não podem ser desconsideradas no momento da prolação da sentença, pois, conforme leciona Faria (2005b, p. 60), "o preço de uma hermenêutica exclusivamente exegética é o advento de uma jurisprudência coerente, em termos técnico-jurídicos, mas socialmente alienada e eticamente ‘idealista'”.

Propugna-se, por conseguinte, uma análise crítica que, sem desconsiderar as especificidades do processo judicial previdenciário, abarque as condicionantes do fenômeno de judicialização das políticas públicas nessa seara, partindo das concepções de que o Direito é complexo, dinâmico e multifacetado, não sendo suficiente considerá-lo 
tão somente por seu aspecto normativo ${ }^{3}$, e de que "a Justiça Social é condição e consequência do Estado Democrático de Direito, e, portanto suas instituições devem a ela submeter-se" (FORTES, 2005, p. 238).

\section{A caracterização do processo judicial previdenciário e o conceito de políticas públicas: um diálogo necessário}

\subsection{Os contornos da lide previdenciária: um processo "diferenciado"}

Os objetivos constitucionalmente previstos de erradicação da pobreza e da marginalização, de redução das desigualdades sociais e regionais e de construção de uma sociedade livre, justa e solidária (art. $3^{\circ}$, I e III, CF), bem como o princípio da dignidade da pessoa humana, compreendido enquanto vértice interpretativo de todo o texto constitucional, devem fundamentar a atuação judicial na seara dos direitos sociais, notadamente, no âmbito da justiça previdenciária, que é o foco deste trabalho. De acordo com Savaris (2011, p. 57), "a lide previdenciária apresenta singularidades que justificam, em certa medida, a condução do direito processual a partir de critérios outros que não os previstos pelo processo civil comum".

Fundamentando sua proposição, o autor em questão apresenta quatro características que conformam a singularidade da lide previdenciária4:

3 "A legislação abrange, sempre, em maior ou menor grau, o Direito e o Antidireito: isto é, Direito propriamente dito, reto correto, e negação do Direito, entortado pelos interesses classísticos e caprichos continuístas do poder estabelecido. [...] O Direito autêntico e global não pode ser isolado em campos de concentração legislativa, pois indica os princípios de normas libertadores, considerando a lei um simples acidente no processo jurídico, e que pode, ou não, transpor as melhores conquistas. [...] Nosso objetivo é perguntar, no sentido mais amplo, o que é Direito (com ou sem leis), mas é preciso esclarecer, igualmente, que nada é, num sentido perfeito e acabado; que tudo é, sendo. [...] Esta luta faz parte do Direito, porque o Direito não é uma "coisa" fixa, parada, definitiva e eterna, mas um processo de libertação permanente." (LYRA FILHO, 2006, p. 8-82).

4 Ao longo deste artigo, ao utilizarmos a expressão lide previdenciária estamos fazendo referência à ação previdenciária, que se diferencia por seu conteúdo: "deve versar sobre a concessão, manutenção ou revisão de um ou mais benefícios previdenciários previstos em lei ou sobre o benefício assistencial, pois, ao que nos parece, ações que tratam de crimes contra a previdência ou que têm como objeto as contribuições para custeio do sistema estão mais afetas aos ramos do direito penal e do direito tributário, respectivamente" (SILVA, 2010, p. 57). 
- a fundamentalidade de um bem jurídico previdenciário, isto é, sua natureza alimentar, correspondendo a um direito de relevância social fundamental;

- a presumível hipossuficiência econômica e informacional da pessoa que reivindica uma prestação da previdência social;

- uma suposta contingência que ameaça a sobrevivência digna da pessoa que pretende a prestação previdenciária;

- o caráter público do instituto de previdência que assume o polo passivo da demanda. (SAVARIS, 2011, p. 87)

No que tange à primeira característica, destaca-se que "o direito material cuja satisfação se pretende no processo previdenciário é um bem de índole alimentar, um direito humano fundamental, um direito constitucional fundamental" (ibidem, p. 60). A lide previdenciária versa, portanto, sobre a possibilidade de o segurado sobreviver dignamente, em depender da benevolência de seus pares e/ou sem ter a necessidade de recorrer à assistência social (pública ou privada) ${ }^{5}$.

Tal correlação entre o sistema protetivo social e as contingências sociais legalmente estabelecidas dialoga perfeitamente com a terceira característica supramencionada, uma vez que o autor da ação previdenciária, na maioria das vezes, é o desamparado, o trabalhador acometido de enfermidade, o inválido, o dependente do segurado falecido ou recluso, que vem buscar provimento jurisdicional frente à decisão denegatória da autarquia previdenciária. Por conseguinte, é importante esclarecer que "o bem previdenciário não deve ser visto como um prêmio, uma vantagem ou mesmo uma benesse ao indivíduo [...]. Não há demérito algum em estar em gozo de formal proteção social.

\footnotetext{
5 “A expressão da dignidade humana não será aperfeiçoada sem um esquema de proteção social que propicie ao indivíduo a segurança de que, na hipótese de cessação da fonte primária de sua subsistência, contará com proteção social adequada" (SAVARIS, 2011, p. 61).
} 
Mas também não há glória nisso, senão em seu significado alimentar" (SAVARIS, 2011, p. 48) ${ }^{6}$.

Todavia, talvez seja na caracterização de suas partes que o processo judicial previdenciário mais denote a sua especialidade. Isso porque, conforme exposto, o polo passivo da demanda é ocupado pelo Instituto Nacional do Seguro Social (INSS), autarquia pública federal, dotada de infraestrutura própria e autonomia financeira, representada por procuradores capacitados, selecionados e contratados por meio de concurso público. Enquanto o polo ativo é ocupado por um jurisdicionado que, a priori, pode ser considerado hipossuficiente:

São, grosso modo, as camadas mais sensíveis e excluídas da sociedade que tem de recorrer à via judicial para alcançarem as benesses da Previdência Social, uma vez que administrativamente tal possibilidade já lhes fora negada.

Essa presumida situação adversa dos jurisdicionado fica bem evidenciada justamente por esse fato de que, para baterem às portas do Poder Judiciário, necessariamente antes já Ihes cerraram as do Poder Executivo, tendo em vista a negativa do pleito no âmbito interno do Instituto Nacional do Seguro Social - INSS, autarquia federal responsável pela implementação e manutenção dos benefícios previdenciários. (SERAU JUNIOR, 2004, p. 19)

Ademais, é preciso considerar o que Pereira Netto (2002) denomina de trabalhadores típicos da atual composição do mercado

\footnotetext{
"No imaginário coletivo, todos que buscam a proteção previdenciária - em geral pessoas pobres, desejam fraudar os cofres públicos; enfim, tirar uma vantagem do bem produzido coletivamente. Com base nessa operação, passa-se a tratar esse homem, que busca a proteção previdenciária, como um inimigo público número um. Tudo em nome do equilíbrio das contas públicas. Não estamos dizendo aqui que as fraudes não devem ser punidas. Devem sim e com todo o rigor, em especial no Judiciário. O que não se deve é criar uma presunção de má-fé [...] e a partir dessa presunção de má-fé, construir toda uma argumentação, aparentemente jurídica, para a denegação dos benefícios previdenciários" (CORREIA, 2009, p. 91).
} 
de trabalho, cujas vidas laborais estão preponderantemente definidas pela característica da instabilidade e são, sintética e genericamente, descritas em exemplo ilustrativo:

é instável o trabalhador, que, por exemplo, inicia sua vida laboral por volta dos 14 anos, exercendo atribuições de 'guardinha', aos 16 começa a trabalhar com o pai como servente de pedreiro, aos 19 consegue emprego em uma fábrica de calçados onde permanece por três anos antes de ser dispensado, usufrui por cinco meses do seguro desemprego e por mais dois continua procurando emprego até conseguir uma vaga de 'calheiro' na qual, 'por não ter experiência', passa dois anos sem registro. Após cinco anos de trabalho regular, é novamente dispensado e, com o dinheiro do FGTS, abre uma micro-empresa de corte e costura com as irmãs, uma também desempregada e a outra que deixa o emprego de doméstica, no qual era registrada com salário menor do aquele que efetivamente recebia, para ajudá-lo e também para tentar melhorar de vida. E daí em diante continua uma trajetória não muito diferente da até então relatada, com fracassos, acertos, indefinições, etc. (NETTO, 2002, p. 127)

Conforme se vislumbra, serão esses trabalhadores que, na maioria dos casos, por terem encontrado problemas na concessão de benefícios na esfera administrativa, virão a se socorrer da função realizadora do Poder Judiciário. Não nos olvidemos que, além das dificuldades econômicas, esse trabalhador enfrentará os obstáculos técnicos para postular e ver atendida sua pretensão em juízo, notadamente quando não assistido por advogado ou defensor público, conforme possibilita o artigo 10 da Lei n. 10.259/2001, que instituiu e regulamentou o procedimento nos Juizados Especiais Federais ${ }^{7}$.

\footnotetext{
"Sem dúvida, podemos comparar a lide instaurada entre o jurisdicionado leigo desacompanhado de advogado e a Fazenda Pública, com a mitológica cena do homem comum tentando combater o leviatã. O desequilíbrio existente entre as partes, nesses casos, será absolutamente evidente, afrontando a regra básica e o princípio constitucional da igualdade entre as partes, a respeito do qual o juiz tem o dever de assegurar o equilíbrio processual (art.125, I, CPC)." (TOURINHO NETO; FIGUEIRA JÚNIOR, 2002, p. 192).
} 
Ainda quanto à questão, no âmbito do conceito de hipossuficiência informacional (conceituada como a insuficiência de conhecimento acerca de sua situação jurídica perante o INSS), justificamos nossa opção teórica pelo termo "vulneráveis", em referência aos autores de ações previdenciárias, diferenciando-nos de outros, que preferem utilizar o adjetivo "hipossuficiente". Isso porque, embora compreendamos que, no âmbito da lide previdenciária, a hipossuficiência econômica seja a mais perceptível e acabe se tornando fator agravante da informacional, esta também pode afetar os segurados de classes econômicas mais abastadas e, por esse motivo, também podem ser considerados "vulneráveis" quando em litígio contra o órgão público de gestão do Regime Geral da Previdência Social (embora não sejam economicamente hipossuficientes).

Em suma, no processo previdenciário, o autor da demanda presume-se hipossuficiente e destituído, total ou parcialmente, de meios necessários à sua subsistência. Esses recursos de natureza alimentar são pressupostos para o exercício da liberdade real do indivíduo e indispensáveis à afirmação da dignidade humana. Temos, portanto, alguém presumivelmente hipossuficiente na busca de um bem da vida de superior dignidade e com potencialidade para colocar um fim no seu estado de privação de bem-estar e de destituição. No pólo passivo da demanda, tem-se a entidade administradora do Regime Geral da Previdência Social, [...], com as dificuldades já notórias no que diz respeito ao atendimento de seus beneficiários na esfera administrativa e cumprimento das determinações judiciais. (SAVARIS, 2011, p. 67)

Diante do exposto, torna-se lícito sustentar que o processo judicial previdenciário tem características muito próprias, que o distanciam dos ditames generalizantes do processo civil. Em especial, porque as ações previdenciárias dialogam de forma muito direta com a realidade concreta de seus sujeitos, não sendo suficientes as abstrações da lógica formal e os reducionismos homogeneizantes da lógica econômica para alcançarse a justeza da decisão. 


\subsection{A necessária mudança de paradigma na atuação do Poder} Judiciário: substituição da lógica econômica por "lógicas de vida"

As discussões acerca dos parâmetros que norteiam a atividade judicial no âmbito previdenciário, como todo debate que toca questões jurídicas muito além do aspecto dogmático, carregam forte conteúdo ideológico, embora ainda existam atores que insistam em proclamar o discurso falacioso da "neutralidade" do ordenamento jurídico.

[...] contrariamente ao que defende a doutrina liberal do Estado de Direito, o jurídico é antes de mais nada político; o direito positivo não é uma dimensão autônoma do político e um fundamento do Estado, mas uma forma constitutiva do mesmo e submetido a suas determinações gerais. Neste particular, o culto da lei e a separação dos Poderes se interpõem como véus ideológicos que dissimulam e invertem a natureza eminentemente política do direito. (LEAL, 2006, p. 171)

Importa ressaltar que tanto a doutrina quanto a jurisprudência têm trabalhado quase exclusivamente com o aspecto técnico do direito previdenciário, privilegiando questões de cunho dogmático e furtandose à necessária discussão, mais aprofundada e complexa, acerca dos paradigmas teóricos e princípios conformadores da previdência social e, de forma mais abrangente, do próprio sistema de seguridade social. Ao que nos parece, há uma prevalência da característica do "seguro" em detrimento do "social": "a segurança social foi substituída, enquanto conceito jurídico, por segurança econômica (e segurança econômica é segurança circunstancial)" (CORREIA, 2006, p. 128).

Essa opção metodológica de abordagem, em geral, funda-se em dois argumentos centrais: a existência do famigerado déficitprevidenciário a ameaçar a saúde econômica de todo o sistema protetivo e, por consequência, a incidência - quase em posição hierárquica superior - do princípio da preservação do equilíbrio financeiro e atuarial ${ }^{8}$, única forma

8 Princípio introduzido via emenda constitucional (EC n. 20/98), em meio ao que Ugatti (2009, p. 17-23) denominou de tsunami neoliberal, ou seja, a política estatal que privilegiou, como diretriz de atuação, o critério de eficiência econômica, em detrimento da justiça social. 
apontada para evitar-se o colapso da previdência social brasileira. No entanto, tais argumentos se encontram "contaminados" pela ideologia liberal $^{9}$ reinante, que, por meio do discurso da racionalidade, busca convencer-nos da "certeza meridiana e da pureza matemática" de suas construções ideológicas.

Ressalta-se que, especialmente ao longo da década de 1990, foi arquitetado o mito do déficit orçamentário da previdência ${ }^{10}$ como estratégia legitimadora das contrarreformas ${ }^{11}$ neoliberais, que visavam o desmonte do projeto constitucional de construção de um sistema de seguridade social no Brasil. A tese de que os gastos sociais demandados pelas disposições contidas no novo texto constitucional tornariam o país "ingovernável" foi amplamente difundida, com o escopo de sedimentar as propostas neoliberais como única solução possível para o controle dos déficits públicos. Em consonância com essa estratégia, foi adotada uma série de medidas legislativas e econômicas - algumas eivadas de flagrante inconstitucionalidade - que acabaram por comprometer de forma bastante significativa o padrão de proteção social instituído pela Constituição de 1988.

Fagnani (2009) afirma que, dentre as medidas adotadas, destacamse a captura de recursos vinculados ao orçamento da seguridade social para o financiamento do déficit público ${ }^{12}$ e o não cumprimento da obrigatoriedade constitucional de transferência de recursos fiscais para

9 Na conjuntura atual de globalização homogeneizante, massiva e opressora, a democracia liberal ou neoliberal surge como único e verdadeiro padrão de organização institucional, baseado na liberdade tutelada pela lei, na igualdade formal, na certeza jurídica e no equilíbrio entre os poderes do Estado. (LEAL, 2000, p. 171)

10 Para uma discussão mais aprofundada sobre a questão, ver Ferreira (2009, p. 149-180; SALVADOR, 2007; GENTIL, 2008; Parcerias: UNICAMP, CESIT, IE - Instituto de Economia. p. 355-371; BATICH, 2010, p. 245-265).

11 Para uma crítica preliminar à concepção de "reforma" do Estado ao longo da década de 1990, ver Behring (2008, p. 196-212).

12 "De forma inovadora, o legislador determinou a criação de um orçamento com recursos próprios e exclusivos para as políticas da seguridade social (saúde, previdência e assistência social), distinto daquele que financia as demais políticas de governo. Entretanto, o orçamento da seguridade social tornou-se "letra morta" na constituição. Todos os governos que passaram pelo Palácio do Planalto desde 1988 não transformaram o dito constitucional em ação efetiva. Pelo contrário, 
financiar a seguridade social. Ademais, salienta-se a utilização de uma metodologia enviesada para a feitura dos cálculos e a apresentação dos dados estatísticos referentes à seguridade social, porquanto tal metodologia não observe os ditames constitucionais no tocante à consideração das receitas e despesas do sistema, "construindo" um resultado deficitário que não corresponde à realidade constitucional vigente. Tal sistemática vem sendo denunciada há anos por estudiosos ligados ao campo das políticas públicas sociais ${ }^{13}$, tais como Rosa Maria Marques, Elaine Behring, Evilásio Salvador e o próprio Eduardo Fagnani (2009, p. 17-23), o qual atesta:

A previdência social foi particularmente vítima dessa estratégia alarmista e falaciosa. O discurso oficial era claro e direito: as causas do déficit da previdência eram os novos direitos, cujos impactos financeiros 'não foram avaliados pelos constituintes'; estes, de forma 'irresponsável', criaram 'despesas sem contrapartida de receitas'; logo, caso o Congresso Nacional não apontasse novas fontes de financiamento ou cortasse despesas pré-existentes, a única alternativa técnica possível era negar a concessão dos novos direitos.

De fato, a opção escolhida como parâmetro de atuação dos órgãos administrativos e judiciais competentes para aplicar a

apropriaram- se das contribuições sociais destinadas para fins da seguridade social, utilizando-as para outras políticas de cunho fiscal, até mesmo para o pagamento dos encargos financeiros da União (amortização e juros da dívida) e para realização de "caixa", visando garantir o superávit primário, principalmente nos anos recentes". (SALVADOR, 2007, p. 82)

13 A própria Associação Nacional dos Auditores Fiscais da Previdência Social (ANFIP) tem uma série de trabalhos em que contesta a metodologia de cálculo oficial aplicada na contabilidade da Seguridade Social (ver a série Boletim Políticas Sociais: Acompanhamento e Análise). Suas conclusões vão no sentido de que há saldo positivo no sistema mesmo quando se agregam os valores gatos com benefícios assistenciais ao montante dos benefícios previdenciários contributivos. Em alguns anos, o saldo é positivo até mesmo quando se agregam os gastos com previdência dos servidores públicos federais (encargos previdenciários da união - EPU), apesar dessa agregação ser conceitualmente uma anomalia diante dos preceitos constitucionais. Ou seja, quando os recursos arrecadados são efetivamente alocados para os seus fins, o resultado contábil da Seguridade é um saldo positivo, e não deficitário. 
legislação previdenciária foi a da denegação de benefícios sob o argumento do controle atuarial e preservação da "saúde financeira" do sistema. Todavia, mesmo diante da brevidade da exposição feita, é possível constatar que os principais argumentos justificadores das interpretações restritivas e violadoras de direitos fundamentais relativos à previdência são, em sua essência, falácias contabilmente erigidas que não se sustentam ante uma análise mais criteriosa. Por isso, é de relevo que se promova a desconstrução teórica e prática do mito do déficit previdenciário, ressaltando-se seu compromisso ideológico na preservação de um padrão de iniquidade na distribuição das riquezas socialmente produzidas. Semelhante tarefa, no campo de atuação do Poder Judiciário, tendo em vista a sua responsabilidade na prolação da "palavra final" em matéria de direitos previdenciário, somente pode ter efetividade por meio de uma interpretação jurídica verdadeiramente comprometida com a realização concreta e cotidiana dos direitos sociais.

Numa demanda em que há fracos e fortes, impõe-se uma atuação judicial tendente a equilibrar as desigualdades, mas isso não parece tão óbvio quando se está diante de uma entidade pública responsável pela gestão dos recursos da previdência social, em tempos de insegurança econômica, anúncios de crise orçamentária e sucessivas reformas previdenciárias. Nessa atmosfera, emerge um falso dilema: analisa-se a pretensão do autor, que se reportaria a um interesse individual, em face do interesse público na preservação do sistema previdenciário. Mas não há interesse social somente na economia de recursos previdenciários, mas fundamentalmente na sua devida aplicação. (SAVARIS, 2011, p. 66)

A responsabilidade dos magistrados é aumentada diante da continuidade, no âmbito da administração pública, da racionalidade técnico-economicista, pela qual "[o] critério para aferir a eficiência não é o da cidadania" (BEHRING, 2008, p. 259). Ainda hoje, na maioria dos casos, as agências da autarquia previdenciária avaliam a concessão de benefícios a partir de "critérios milimétricos estabelecidos pela legislação previdenciária" (SAVARIS, 2011, p. 51), ou seja, em conformidade com 
a lógica positivista14, preocupada em alcançar a "verdade", a "solução universal", que será aplicada aos casos semelhantes, sob o mote do "tratamento igualitário". Entretanto, é preciso deixar claro que todo esse discurso escamoteia uma lógica econômica que propicia a inversão do polo fraco na relação processual previdenciária: não será mais o indivíduo vulnerável econômica e informacionalmente o carente de proteção e cuidado especial, e sim o próprio sistema previdenciário, que deve ser preservado para o bem de todos, ainda que esse "todos" implique no sacrifício de alguns (muitos) ${ }^{15}$. É nesse contexto, portanto, que ganha relevo a atuação de magistrados e tribunais, porquanto,

a aplicação estrita das regras previdenciárias genéricas dispostas em lei e em atos infralegais pode ser admitida na esfera administrativa, pois os agentes administrativos, especialmente os que se encontram na frente de concessão da entidade previdenciária, não têm maior espaço para interpretação.

Mas não deve ser assim no processo judicial previdenciário, onde temos a figura do juiz como órgão jurisdicional chamado a examinar, na instância derradeira (judicial), o direito da pessoa subsistir por intermédio da proteção social. O processo judicial previdenciário é o campo próprio para soluções de equidade, afastando-se do método cartesiano de reputar falso o que é apenas provável. (SAVARIS, 2011, p. 47)

Salienta-se que essa solução por equidade não se encontra desprovida de parâmetros reguladores, não havendo que se falar em

14 "Este é o juiz positivista previdenciário: um sujeito que condiciona o direito a um resultado impraticável (juízo de certeza nas ciências humanas), a uma prova insofismável; Avesso às emoções, repudia a dúvida e toda incerteza, as analogias, as presunções e tudo quanto os seus olhos e a sua realidade social não dominem. [...] O grau de certeza que exige uma condenação criminal é a medida de certeza a que condicionará a concessão da sobrevivência. Insuficiente fosse a desgraça, esconde suas incertezas numa retórica que lhe distancia do humano que julga e lhe aproxima da imprudência". (SAVARIS, 2011, p. 52).

15 Diferentemente da verdade do saber das ciências da natureza, não deve haver no processo judicial previdenciário a busca pela universalização do caso individual como condição para o reconhecimento da verdade. [...] na interpretação dos fatos e das normas no âmbito dos direitos socais, a verdade a ser alcançada deve ser aquela que tenha o homem e sua contingência de destituição e ameaça à sobrevivência como referência primeira. Uma verdade que não precisa ser universalizável ou posta à prova da generalização. (SAVARIS, 2011, p. 47-51). 
discricionariedade ou, como têm defendido alguns autores, em ditadura do Judiciário. A atuação do Poder Judiciário no âmbito das políticas públicas de previdência social deve se dar em obediência aos parâmetros pré-estabelecidos pelo texto constitucional, em consonância ao que Leal (2006) denominou de conceito de políticas públicas constitucionais vinculadas, as quais são:

independentes da vontade ou discricionariedade estatal para que venham a acontecer, eis que condizentes a direitos indisponíveis e da mais alta importância e emergência comunitária, perquirindo imediata materialização, sob pena de comprometer a dignidade humana e o mínimo existencial dos seus carecedores. De certa forma, quando estas políticas públicas ou ações estratégicas dos Poderes competentes não ocorrem, o Poder Judiciário no Brasil é chamado à colação. [...]

Daqui resulta que o Poder Judiciário (ou qualquer outro Poder Estatal) não tem o condão de make public choices, mas pode e deve assegurar aquelas escolhas públicas já tomadas por estes veículos, notadamente as insertas no Texto Político, demarcadoras dos objetivos e finalidades desta República Federativa. São tais indicadores que estão a reivindicar políticas públicas constitucionais vinculantes para serem concretizados. Quando não efetivadas, dão ensejo à legítima persecução republicana para atendê-las, administrativa, legislativa e jurisdicionalmente. (grifo nosso)

Portanto, o que se preconiza, em verdade, é a necessidade de substituir o critério de rentabilidade econômica pelo de satisfação das necessidades humanas básicas ${ }^{16}$, com a finalidade precípua de dar

16 "[...] não se trata de ignorar a responsabilidade humana com os caminhos da própria existência, mas de contribuir para a construção de uma racionalidade compromissada com o reconhecimento recíproco, de modo não hierárquico - tendo de um lado, os vencedores e de outro, os perdedores em que o critério vetor contextual seja a democratização do acesso aos bens frutos do labor social, e não a acumulação de capital e a eficiência econômica descompromissada com a erradicação da miséria e a redução das desigualdades sociais." (UGATTI, 2009, p. 196) 
efetividade aos direitos humanos e fundamentais constitucionalmente assegurados, no âmbito dos quais se encontra a proteção previdenciária, pois, conforme atesta Savaris (2011, p. 132) $)^{17}$ "eficiência econômica aplicada à previdência social significa obsessão por redução de custos, com desajustes sociais e graves consequências humanas".

Tal diretriz de atuação jurídico-política, na medida em que recupera os padrões de proteção social dispostos na Constituição Federal de 1988 e sistematicamente desvirtuados pelas políticas econômicas de vertente neoliberal, tem o condão de afastar a "banalização do mal", escamoteada em discursos que atribuem a adversidade do desemprego e da exclusão à causalidade do destino, à causalidade econômica ou à causalidade do sistema (fenômeno da "naturalização da pobreza ${ }^{18 "), ~}$ não problematizando as origens de tais "infortúnios".

17 "É isso o que buscam as reformas previdenciárias restritivas de direitos e as que promovem elevação de receitas: um sistema previdenciário eficiente, que maximize seus recursos e ademais gere excedentes. Mas na sua face oculta e mais dramática, a busca pela eficiência previdenciária se revela na dificuldade de acesso à tutela administrativa, na falta de mínima inclinação do órgão gestor à solução dos problemas dos administrados, no prematuro encerramento dos processos administrativos e na multiplicação de ilegais óbices à concessão de benefícios. Afinal, o que motiva os agentes previdenciários, senão a eficiência (econômica)?" (SAVARIS, 2011, p. 132)

18 "Por outro lado, nem todos partilham hoje o ponto de vista segundo o qual as vítimas de desemprego, da pobreza e da exclusão social seriam também vítimas de uma injustiça. Em outras palavras, para muitos cidadãos, há aqui uma clivagem entre sofrimento e injustiça. Essa clivagem é grave. Para os que nela incorrem, o sofrimento é uma adversidade, é claro, mas adversidade não reclama necessariamente reação política. Pode justificar compaixão, piedade ou caridade. Não provoca necessariamente indignação, cólera ou apelo à ação coletiva. $\mathrm{O}$ sofrimento somente suscita um movimento de solidariedade e de protesto quando se estabelece uma associação entre percepção do sofrimento alheio e a convicção de que esse sofrimento resulta de uma injustiça. Evidentemente, quando não se percebe o sofrimento alheio, não se levanta a questão da mobilização numa ação política, tampouco a questão da justiça e injustiça. [...] As pessoas que dissociam sua percepção do sofrimento alheio do sentimento de indignação causado pelo reconhecimento de uma injustiça adotam frequentemente uma postura de resignação. [...] Segundo essa concepção, não haveria injustiça, mas apenas um fenômeno sistêmico, econômico, sobre o qual não se poderia exercer nenhuma influência." (DEJOURS, 2007, p. 19-20) 


\section{A judicialização das políticas públicas relativas à previdência social}

2.1 Exigência do indeferimento administrativo como condição da ação: discussões em torno do princípio da tripartição dos poderes

Postas as premissas teóricas que fundamentam nossa argumentação, cumpre agora discorrer sobre as nuances da atuação do Poder Judiciário em matéria de direitos previdenciários, refletindo, sobretudo, acerca da temática probatória. Tal reflexão faz-se necessária porquanto no "Estado Democrático Contemporâneo, a eficácia concreta dos direitos constitucional e legalmente assegurados depende da garantia da tutela jurisdicional efetiva, porque sem ela o titular do direito não dispõe da proteção necessária do Estado ao seu pleno gozo" (GRECO, 2002, p. 11).

No que tange à ação previdenciária, já há muito se discute acerca da (des)necessidade de prévio ingresso administrativo como condição para a propositura de ação judicial. Parte da doutrina e dos juízes entendia que tal exigência poderia ferir o direito de ação garantido no art. $5^{\circ}, X X X V$, da Constituição Federal. No entanto, por força desse mesmo dispositivo, é forçoso que se reconheça que somente a "lesão ou ameaça a direito" gozam da proteção referida, necessitando ser provada, o que acontecerá, via de regra, pelo indeferimento administrativo. Assim, consubstancia-se o interesse de agir e se completa uma condição da ação que, somada às demais (legitimidade de parte e possibilidade jurídica do pedido), justifica a necessidade de uma prestação jurisdicional. Conforme destaca Theodoro Júnior (1999, p. 53):

Localiza-se o interesse processual não apenas na utilidade, mas especificamente na necessidade do processo como remédio apto à aplicação do direito objetivo no caso concreto, pois a tutela jurisdicional não é jamais outorgada sem uma necessidade. [...] Só o dano ou o perigo de dano jurídico representado pela efetiva existência de uma lide, é que autoriza o exercício do direito de ação. 
Por outro lado, é importante que se lembre de que basta a negativa ao requerimento ou mesmo a simples demora injustificada em se dar uma resposta, por parte do INSS, para que se configure a pretensão resistida. No primeiro caso, há inclusive a Súmula $n$. 9, do Tribunal Regional Federal da $3^{a}$ Região, segundo a qual "em matéria administrativa, torna-se desnecessário o prévio exaurimento da via administrativa, como condição de ajuizamento da ação" (basicamente o mesmo teor da Súmula 213, do extinto Tribunal Federal de Recursos). Interessante ainda a observação de Serau Junior (2006, p. 221), para quem a conduta reiterada da autarquia previdenciária (deduzindo em sua defesa a necessidade do prévio esgotamento das vias administrativas)

[...] poderia inclusive ser enquadrada nas condutas tipificadas no art. 17 do CPC, que trata da litigância de máfé, posto que o objetivo do INSS em alegar a necessidade do prévio esgotamento das vias administrativas para demarcar o interesse processual só pode ser, nos dias de hoje, o de procrastinar o feito, dado dificultar ou ao menos prolongar a análise dos autos que tramitam perante o Judiciário, uma vez que se rejeita unanimemente essa alegação [...].

Já no segundo caso (demora na resposta), o Dec. n. 3048/99, art. 174, define o período de 45 dias como data-limite para o primeiro pagamento do benefício, portanto, sua concessão ou negativa deve acontecer em prazo inferior a esse.

Finalmente, destaca Savaris (2009, p. 65): "com essas questões e com outras que dizem respeito ao tema 'interesse de agir em matéria previdenciária', a doutrina e jurisprudência do processo civil clássico nem cuida em preocupar-se", portanto, cabe aos estudiosos dessa área específica do Direito o trabalho de sistematizar a matéria, suas dificuldades e tendências, servindo, em especial, como subsídio às decisões jurisprudenciais.

Tavares (2009, p. 13), apesar de reconhecer que as características próprias das lides previdenciárias não existem em intensidade suficiente para justificar a existência de uma codificação própria, alega que isso 
não invalida a necessidade de desenvolvimento de uma teoria do processo previdenciário. Somente assim seriam "evitadas injustiças materiais através de um processo não adaptado à realidade do seguro ou mal utilizado a partir da desconsideração de suas particularidades".

Tais posicionamentos se coadunam com a premissa teórica de que a invocação constante e sistematizada do princípio da tripartição dos poderes enquanto óbice para a judicialização das políticas públicas constitui, na verdade, uma argumentação retórico-ideológica, comprometida com a manutenção da ordem econômica e social excludente ${ }^{19}$.

Historicamente, como afirma Cappelletti, todas as vezes em que a tradicionalmente rígida separação entre poderes independentes e autônomos não permitiu a emergência de um sistema de controle e contrapesos recíprocos, com os magistrados podendo exercer funções mais amplas do que as previstas pelo paradigma liberal clássico de Estado de Direito, o resultado foi "um Judiciário perigosamente débil e confinado, em essência, aos conflitos privados", apenas onde esse sistema de controles e contrapesos recíprocos se consolidou é que se conseguiu, "sem perigo para a liberdade, fazer coexistir [...] um Executivo forte com um Judiciário forte. (FARIA, 2005b, p. 65)

Conforme se atesta, mesmo sob a perspectiva normativista, não há que se falar em ditadura do Poder Judiciário, pois a própria legislação fixou o critério do prévio indeferimento administrativo como condição para

19 "Na tradição da Democracia Liberal brasileira, desde os seus primórdios, sempre se designou como único e verdadeiro padrão de organização institucional da sociedade brasileira o baseado na liberdade tutelada formalmente pela lei, na igualdade formal, na certeza jurídica, no equilíbrio entre os Poderes do Estado, forjando uma unanimidade sobre a pertinência de atitudes, hábitos e procedimentos, os quais, geralmente, refletiam a reprodução do status quo imposto pelo modelo de desenvolvimento econômico excludente que até agora se teve. Em tal quadro, competiu ao Estado de Direito tão-somente regular as formas de convivência social e garantir sua conservação; a economia se converteu numa questão eminentemente privada, e o direito, por sua vez, tornou-se predominantemente direito civil, consagrando os princípios jurídicos fundamentais ao desenvolvimento capitalista, como os da autonomia da vontade, da livre disposição contratual e o do pacta sunt servanda" (LEAL, 2006, p. 171). 
ajuizamento e conhecimento da ação judicial previdenciária. No âmbito organizacional do Estado Democrático de Direito, é crível que se reconheça a todos os poderes instituídos, inclusive ao Judiciário, a competência e o dever institucional de se comprometerem com a efetivação dos ditames constitucionais, protegendo quem efetivamente detém, em última instância, a soberania do poder - o povo -, não por desvio ou excesso ideológico de crença política, mas pautado pela obrigação de garantir a ordem republicana e democrática de desenvolvimento do Brasil, sob pena de aprofundar, ainda mais, suas crises de identidade, eficácia e legitimidade social (LEAL, 2006, p. 176).

2.2 A possibilidade de maior amplitude probatória enquanto condição de afirmação dos direitos previdenciários

Garantia da ampla defesa, seja no âmbito administrativo ou judicial, a prova em Direito Previdenciário assume a relevância ímpar de condicionante do acesso a um direito fundamental. Ainda antes de qualquer eventual litígio inter partes, quando um segurado requer um benefício, ele se obriga a convencer a autarquia de seu direito. Deixando à parte a discussão de que, em muitos desses casos, essa prova seria absolutamente dispensável se a própria autarquia tivesse um controle mais eficaz de seus registros, recebimentos e fiscalização, enfim, um banco de dados confiável, em outros casos, cabe ao segurado, em princípio, fazer prova do que alega.

Identificam-se, na doutrina, três sistemas distintos de produção de provas: o da prova legal, o da livre convicção do juiz e o da persuasão racional (ou livre convencimento motivado), tendo sido este último o adotado pelo Código de Processo Civil (CPC) brasileiro. Esse sistema não se baseia na convicção por meio de impressões pessoais, mas na consciência formada pelas provas, condicionadas a regras jurídicas, lógicas e de experiência. Pesam também os princípios constitucionais, os quais têm especial relevância no Direito Previdenciário, a fim de possibilitar o acesso aos direitos fundamentais por meio da garantia da utilização dos meios de prova necessários para comprovar o direito do beneficiário. 
A descoberta da verdade é o adequado elemento funcional do conceito de prova, como pressuposto da realização da justiça e da tutela jurisdicional efetiva dos cidadãos. Os obstáculos à realização desse objetivo devem ser, sempre que possível, removidos e as dificuldades em alcançá-lo não devem atirar-nos no ceticismo ou na falácia de soluções redutoras, como as da verdade formal, do julgamento fortemente influenciado por presunções ou por valorações probatórias aprioristicamente estabelecidas. (GRECO, 2003-2004, p. 259-260)

Não obstante o ensinamento de Greco (2003-2004), a legislação previdenciária tem supervalorizado as regras legais da produção de prova, em detrimento de outros aspectos contidos no sistema de persuasão racional, resultando em um retrocesso, devido à aproximação com o superado sistema da prova legal. Isso tem contribuído para dificultar a comprovação dos fatos alegados pelos beneficiários, em especial, no âmbito administrativo, pois

Como consequência de uma suposta aliança de particulares que se lançam contra a Administração Previdenciária, esta opera como uma 'cidade sitiada', de modo que a análise do direito passa por um crivo administrativo que, por vezes, não vê o evidente e enxerga o que não existe. (SAVARIS, 2009, p. 239)

Tais circunstâncias tornam quase inevitáveis a remessa dessas lides ao Poder Judiciário, onde, é claro, a apreciação das provas também estará vinculada às condições impostas pela lei, mas o magistrado não poderá desconsiderar os fins sociais das normas e a própria realidade social. Como já ressaltado, a convicção do juiz não deve ser resultado de mera atividade lógico-formal, e sim, de uma apreciação crítica com base no contexto social vigente, utilizando o processo como instrumento de garantia dos direitos fundamentais, não como um fim em si mesmo.

Paradigmático, por se tratar de um dos problemas mais reincidentes nos processos previdenciários, é o caso da prova de tempo de serviço, em especial dos trabalhadores rurais, em que o magistrado deverá ponderar dois bens fundamentais: um coletivo (maior segurança na 
concessão de benefícios previdenciários) e outro individual (o direito ao benefício e à produção das eventuais provas possíveis para assegurálo).

Considerando-se que, nesse caso, a legislação é restritiva, pois impõe a necessidade de "início de prova material, não sendo admitida prova exclusivamente testemunhal" (art. 55, §3º, Lei n. 8.213/91), fica evidente a necessidade da aplicação do princípio da proporcionalidade, o qual, segundo destaca Savaris (2009, p. 232), "se encontra na essência da técnica da ponderação de bens e na aferição da constitucionalidade de algumas leis restritivas", tornando-se instrumento de verificação de "inconstitucionalidade por excesso de poder legislativo". Ademais, é sempre pertinente a indagação: o que fazer diante de casos nos quais as únicas provas do trabalho rural realizado são as mãos calejadas do segurado e os olhos de quem testemunhou seu labor? Em resposta a indagações dessa natureza, o magistrado paranaense atesta:

Quando propugnamos a verdade real para o direito processual previdenciário, estamos nos referindo a um conhecimento que não se contenta com o que the propicia automaticamente a forma processual, mas busca compreender, mediante aproximação das realidades que cercam os fatos, o objeto que desafia a interpretação. [...] A solução pro misero deve ser aplicada quando, em uma perspectiva formal, qualquer dos resultados dispostos pela sentença pareça razoável. $\mathrm{Na}$ dúvida, decidese casuisticamente evitando-se o sacrifício de direito fundamental. (SAVARIS, 2011, p. 48)

Nesse diapasão, os critérios e requisitos legalmente estabelecidos para a concessão dos benefícios previdenciários passam a ser concebidos como diretrizes gerais de atuação (não totalitárias e não passíveis de generalização), representando, pois, pressupostos legítimos para diminuir o risco moral do sistema de proteção social, isto é, a fragilidade da previdência social em face de ações oportunísticas por parte de alguns de seus beneficiários. Todavia, no processo de tomada de decisão, o Juiz deve atentar para o fato de que os "detalhes geométricos da legislação previdenciária podem levar a juízos de 
iniquidade, a situações em que se desconsidera todo o histórico de vida do trabalhador ou a necessidade real de proteção social" (SAVARIS, 2001, p. 48-49).

Caberia ainda mencionar outras situações em que o processo previdenciário se particulariza pela necessidade de admitir maior amplitude probatória. Veja-se, por exemplo, o caso das perícias nas aposentadorias por invalidez, quando a doutrina ${ }^{20}$ e a tendência jurisprudencial $^{21}$ já se firmam no sentido de que a incapacidade laboral não pode ser aferida apenas a partir de uma perspectiva médica, devendo levar em consideração aspectos etários, qualificação profissional, condição socioeconômica etc. Dessa forma, o magistrado não está adstrito ao laudo médico pericial, podendo considerar outros elementos presentes nos autos.

Mais uma vez, sobreleva a importância de se analisar o caso concreto, com todas as suas especificidades, para se aproximar ao máximo da justiça social que se busca. Cada trabalhador está inserido em um contexto e é dotado de uma história de vida única, portanto, para que o Direito cumpra sua função transformadora, é essencial que sua aplicação se dê dentro de uma perspectiva complexa, a qual implica em uma análise mais abrangente, somente possível a partir da admissão de diversas possibilidades de prova do fato alegado.

As partes ou os interessados na administração da Justiça devem ter o direito de apresentar todas as alegações, propor e produzir todas as provas que, a seu juízo, possam militar a favor do acolhimento da sua pretensão ou do não acolhimento da postulação do seu adversário. Esse direito abrange tanto o direito à auto-defesa quanto à defesa técnica por um advogado habilitado, e também o direito a

\footnotetext{
20 Veja-se, a propósito: FORTES, Simone Barbisan; PAULSEN, Leandro. Direito da seguridade social. Porto Alegre: Livraria do Advogado, 2005. p. 111; CASTRO, Carlos A. P.; LAZZARI, João B. Manual de Direito Previdenciário. 8.ed. Florianópolis: Conceito Editorial, 2007. p. 481; entre outros.

21 Exemplificando, as decisões contidas em: AgRg no REsp. n. 1229.147-MG (2010/0226035-4), julg. em 17.03.11; AgRg no REsp. 1056545-PB - 5 ${ }^{\mathrm{a}} \mathrm{T}$, julg. em 18.11.10; e AgRg no Ag 1102739GO - 6 ${ }^{\mathrm{a}}$, julg. em 20.10.09.
} 
não ser prejudicado no seu exercício por obstáculos alheios à sua vontade ou pela dificuldade de acesso às provas de suas alegações. (GRECO, 2002, p. 18, grifo nosso)

Em suma, a necessidade de maior amplitude probatória no Direito Previdenciário aparece também como instrumento que busca uma "paridade de armas" entre segurado e INSS, indispensável, portanto, à tutela do direito à proteção social. Busca-se, no reconhecimento do "outro" (no caso, o trabalhador) e da realidade em que ele está inserido, uma maior aproximação da verdade real, aferível apenas quando nos dispomos ao desapego dos formalismos e das interpretações normativas literais.

\section{Conclusão}

Toda a argumentação desenvolvida teve a pretensão de expor a necessidade de se retomar as discussões atinentes à judicialização das políticas públicas em matéria previdenciária a partir de outras perspectivas, que não se mostrem indiferentes às conjunturas social, econômica e política que permeiam todo e qualquer fenômeno jurídico. Nesse sentido, propugna-se por mudanças nos paradigmas que orientam a atuação de magistrados e tribunais no âmbito dos processos judiciais previdenciários, ressaltando-se o fato de que a previdência social é um direito humano fundamental, já largamente positivado, cuja efetivação é pressuposto de concretude do princípio maior da dignidade da pessoa humana.

Assim, seja no tocante ao seu objeto (direito humano e fundamental), seja quanto à situação fática que a caracteriza (demanda por prestação alimentar, em geral, em condições que exigem urgência na prestação jurisdicional - enfermidade, incapacidade, dependência econômica de segurado falecido ou recluso), ou, ainda, no que tange à disparidade de forças entre suas partes (situação de vulnerabilidade do segurado diante da autarquia previdenciária), o fato é que resta evidenciada a especialidade da lide previdenciária, tornando-se necessária a teorização acerca de um "olhar diferenciado", menos 
técnico-econômico e mais demasiadamente humano, um olhar que seja capaz de vislumbrar o Outro e suas condicionantes, compreendendo que não há "medida abstrata de justeza": a justiça se realiza em cada decisão.

Diante do predomínio de uma lógica de eficiência econômica no âmbito da administração pública, em que há o claro predomínio da característica do "seguro" em detrimento da do "social", o Poder Judiciário acaba se configurando na instância última capaz de socorrer o segurado e seus dependentes, sanando as arbitrariedades, irregularidades e excessos legalistas de interpretações restritivas que, calcadas no falso dilema "individual-coletivo", só fazem afastar o direito à proteção previdenciária da vida - e do cotidiano - daqueles e daquelas que dela mais necessitam.

\section{Referências}

ABRANCHES, Sérgio. Questão social, previdência e cidadania no Brasil. In: GOMES, Angela de Castro (Org.). Trabalho e previdência: 60 anos em debate. Rio de Janeiro: Fundação Getúlio Vargas/CPDOC, 1992. p. 74-80.

BEHRING, Elaine Rossetti. Brasil em contra-reforma: desconstrução do Estado e perda de direitos. 2. ed. São Paulo: Cortez, 2008.

BUCCI, Maria Paula Dallari (Org.). Políticas públicas: reflexões sobre o conceito jurídico. São Paulo: Saraiva, 2006.

CAMPILONGO, Celso Fernandes. Os desafios do Judiciário. In: FARIA, José Eduardo (Org.). Direitos humanos, direitos sociais e justiça. São Paulo: Malheiros, 1994.

CORREIA, Marcus Orione Gonçalves. Direitos humanos e direitos sociais: interpretação evolutiva e segurança social. Revista do Departamento de Direito do Trabalho e da Seguridade Social, São Paulo. v.1, n. 1, p. 117-135, jan./jun. 2006. 
. Princípios informadores da seguridade social e suas implicações cotidianas. In VAZ, Paulo Afonso Brum; SAVARIS, José Antônio (Orgs.). Direito da previdência e assistência social: elementos para uma compreensão interdisciplinar. Florianópolis: Conceito, 2009. p. 81-96.

. Teoria e prática do poder de ação na defesa dos direitos sociais. São Paulo: Ltr, 2002.

DEJOURS, Christophe. A banalização da injustiça social. Tradução de Luiz Alberto Monjardim. Rio de Janeiro: Ed. FGV, 2007.

FAGNANI, E. Os profetas do caos e o debate recente sobre a seguridade social no Brasil. In: FAGNANI, E.; HENRIQUE, W.; LÚCIO, C. Previdência social: como incluir os excluídos? São Paulo: LTr, 2008. p. 3143.

. Seguridade social brasileira: trajetória recente e novos desafios. In: VAZ, Paulo Afonso Brum; SAVARIS, José Antônio (Org.). Direito da previdência e assistência social: elementos para uma compreensão interdisciplinar. Florianópolis: Conceito, 2009. p. 37-79.

FARIA, José Eduardo. Introdução: o Judiciário e desenvolvimento sócio-econômico. In: FARIA, José Eduardo (Org.). Direitos humanos, direitos sociais e justiça. São Paulo: Malheiros, 2005a. p. 11- 29.

As transformações do Judiciário em face de suas responsabilidades sociais. In: FARIA, José Eduardo (Org.). Direitos humanos, direitos sociais e justiça. São Paulo: Malheiros, 2005b. p. $52-67$

. (Org.). Direitos humanos, direitos sociais e justiça. São Paulo: Malheiros, 2005b.

FORTES, Simone Barbisan. Previdência social no Estado democrático de direito: uma visão à luz da teoria da justiça. São Paulo: LTr, 2005.

GRECCO, Leonardo. O conceito de prova. Revista da Faculdade de Direito de Campos, ano IV, n. 4 e ano V, n. 5, 213-267, 2003-2004. Disponível em <http://www.abedir.org/documents/Oconceitodeprova. pdf>. Acesso em: 29 jan 2012. 
- Garantias fundamentais do processo: processo justo. Novos Estudos Jurídicos, Itajaí, ano VII, n. 14, p. 9-68, abr. 2002.

LEAL, Rogério Gesta. O controle jurisdicional de políticas públicas no Brasil: possibilidades materiais. In: SARLET, Ingo Wolfgang (Coord.). Jurisdição e direitos fundamentais: anuário 2004/2005 da Escola Superior da Magistratura do Rio Grande do Sul - AJURIS. Porto Alegre: Livraria do Advogado, 2006. p. 157-178.

- Perspectivas hermenêuticas dos direitos humanos e fundamentais no Brasil. Porto Alegre: Livraria do Advogado, 2000.

LYRA FILHO, Roberto. O que é Direito. São Paulo: Brasiliense, 2006.

NETTO, Juliana Presotto Pereira. A previdência social em reforma: o desafio da inclusão de um maior número de trabalhadores. São Paulo: LTr, 2002.

PELÁEZ, Francisco J. Contreras. Derechos sociales: teoria e ideologia. Madrid: Tecnos/Fundación Cultural Enrique Luño Peña, 1994.

SALVADOR, Evilásio. Quem financia e qual o destino dos recursos da seguridade social no Brasil. Observatório da Cidadania: Dignidade e Direitos: Seguridade Social como Direito Universal, n. 11, 2007. Disponível em <http://www.socialwatch.org/node/9346>. Acesso em: 9 out. 2012.

SAVARIS, José Antônio. Direito processual previdenciário. Curitiba: Juruá, 2009.

Direito processual previdenciário. 3. ed. Curitiba: Juruá, 2011.

SERAU JUNIOR, Marco Aurélio. Curso de processo judicial previdenciário. São Paulo: Método, 2004.

. Curso de processo judicial previdenciário. 2. ed. São Paulo: Método, 2006.

SILVA, Júlia Lenzi. O Jus Postulandi nos juizados especiais federais: (...). 2010. 114 f. Trabalho de conclusão de curso (Bacharelado)- 
Faculdade de Ciências Humanas e Sociais, Universidade Estadual Paulista, Franca, 2010.

TAVARES, Marcelo Leonardo. O devido processo legal previdenciário e as presunções de prova. In: TAVARES, Marcelo Leonardo (Coord.). Direito processual previdenciário: temas atuais. Niterói: Impetus, 2009. p. 23-42.

THEODORO JÚNIOR, Humberto. Curso de direito processual civil. Rio de Janeiro: Forense, 1999. v. 1.

TOURINHO NETO, Fernando da Costa; FIGUEIRA JÚNIOR, Joel Dias. Juizados especiais federais cíveis e criminais: comentários à Lei 10.259/2001. São Paulo: Revista dos Tribunais, 2002.

UGATTI, Uendel Domingues. Limites e possibilidades de reforma na seguridade social. São Paulo: LTr, 2009.

Recebido em: 14/03/12

Aprovado em: 17/08/12 